\title{
Combined H5ND inactivated vaccine protects chickens against challenge by different clades of highly pathogenic avian influenza viruses subtype $\mathrm{H5}$ and virulent Newcastle disease virus
}

\author{
Ahmed Ali ${ }^{1 *}$, Marwa Safwat ${ }^{2 *}$, Walid H. Kilany², Abdou Nagy3,4, Awad A. Shehata ${ }^{5}$, Mohamed A. Zain El-Abideen², \\ Al-Hussien M. Dahshan ${ }^{1}$ and Abdel-Satar A. Arafa ${ }^{2}$
}

1. Department of Poultry Diseases, Faculty of Veterinary Medicine, Beni-Suef University, Beni-Suef 62511, Egypt; 2. Reference Laboratory for Veterinary Quality Control on Poultry Production, Animal Health Research Institute, Dokki, Giza 12618, Egypt; 3. Department of Virology, Faculty of Veterinary Medicine, Zagazig University, Zagazig 44511, Egypt; 4. Department of Veterinary Medicine, Virginia-Maryland Regional College of Veterinary Medicine, University of Maryland, College Park, MD, 20742, USA; 5. Department of Avian and Rabbit Diseases, Faculty of Veterinary Medicine, University of Sadat City, Menoufia 22857, Egypt.

* The authors equally contributed to the manuscript

Corresponding author: Ahmed Ali, e-mail: ahmed.ali1@vet.bsu.edu.eg

Co-authors: MS: marwasafwat13@yahoo.com,WHK: walidhamdy78@yahoo.com, AN: abdonagy58@rocketmail.com, AAS: awad.shehata@vet.usc.edu.eg, MAZEI: rd-super visor@me-vac.com, AMD: hussiendahshan73@vet.bsu.edu.eg, AAA: araby85@hotmail.com

Received: 01-09-2018, Accepted: 30-11-2018, Published online: 21-01-2019

doi: 10.14202/vetworld.2019.97-105 How to cite this article: Ali A, Safwat M, Kilany WH, Nagy A, Shehata AA, Zain El-Abideen MA, Dahshan AM, Arafa AA (2019) Combined H5ND inactivated vaccine protects chickens against challenge by different clades of highly pathogenic avian influenza viruses subtype $\mathrm{H} 5$ and virulent Newcastle disease virus. Veterinary World, 12(1): 97-105.

\begin{abstract}
Aim: The aim of the current study was to evaluate the efficacy of a trivalent-inactivated oil-emulsion vaccine against challenge by different clades highly pathogenic avian influenza (HPAI) viruses including HPAI-H5N8 and the virulent genotype VII Newcastle disease virus (NDV) (vNDV).

Materials and Methods: The vaccine studied herein is composed of reassortant AI viruses rgA/Chicken/Egypt/ ME1010/2016 (clade 2.2.1.1), H5N1 rgA/Chicken/Egypt/RG-173CAL/2017 (clade 2.2.1.2), and "NDV" (LaSota NDV/ $\mathrm{CK} /$ Egypt/11478AF/11); all used at a concentration of $10^{8} \mathrm{EID}_{50}$ /bird and mixed with Montanide-ISA70 oil adjuvant. Two-week-old specific pathogen free (SPF) chickens were immunized subcutaneously with $0.5 \mathrm{ml}$ of the vaccine, and hemagglutination inhibition (HI) antibody titers were monitored weekly. The intranasal challenge was conducted 4 weeks post-vaccination (PV) using $10^{6} \mathrm{EID}_{50} / 0.1 \mathrm{ml}$ of the different virulent HPAI-H5N1 viruses representing clades 2.2.1, 2.2.1.1, 2.2.1.2, 2.3.4.4b-H5N8, and the vNDV.
\end{abstract}

Results: The vaccine induced HI antibody titers of $>6 \log _{2}$ against both H5N1 and NDV viruses at 2 weeks PV. Clinical protection against all HPAI H5N1 viruses and vNDV was 100\%, except for HPAI H5N1 clade-2.2.1 and HPAI H5N8 clade2.3.4.4b viruses that showed $93.3 \%$ protection. Challenged SPF chickens showed significant decreases in the virus shedding titers up to $<3 \log _{10}$ compared to challenge control chickens. No virus shedding was detected 6 "days post-challenge" in all vaccinated challenged groups.

Conclusion: Our results indicate that the trivalent H5ND vaccine provides significant clinical protection against different clades of the HPAI viruses including the newly emerging H5N8 HPAI virus. Availability of such potent multivalent oil-emulsion vaccine offers an effective tool against HPAI control in endemic countries and promises simpler vaccination programs.

Keywords: avian influenza, Egypt, H5N1, H5N8, H5ND, Newcastle diseases virus, trivalent vaccine.

\section{Introduction}

Avian influenza (AI) viruses belong to the family Orthomyxoviridae, genus Influenza virus. To date, 18 hemagglutinin (HA) and 11 neuraminidase subtypes have been reported [1]. During the past decade, poultry industry in Egypt was challenged by exposure to different AI virus subtypes, including the highly pathogenic AI (HPAI) H5N1, low pathogenic AI H9N2,

Copyright: Ali, et al. Open Access. This article is distributed under the terms of the Creative Commons Attribution 4.0 International License (http://creativecommons.org/licenses/by/4.0/), which permits unrestricted use, distribution, and reproduction in any medium, provided you give appropriate credit to the original author(s) and the source, provide a link to the Creative Commons license, and indicate if changes were made. The Creative Commons Public Domain Dedication waiver (http://creativecommons.org/ publicdomain/zero/1.0/) applies to the data made available in this article, unless otherwise stated. and HPAI H5N8 [2-4]. Since AI infections emerged in mid-February 2006, HPAI H5N1 showed several mutations and different sub-clades of the virus. The presence of the virus under vaccine immune pressure in vaccinated birds accelerated its mutation rate [5]. Thus, a repertoire of AI virus clades was reported in Egypt since 2008, including 2.2.1, 2.2.1.1, 2.2.1.2, and 2.2.1.2a clades [6-8].

In the meantime, Newcastle disease (ND) continues to cause serious problems and high economic losses in poultry in Egypt. ND virus (NDV) is an avian paramyxovirus serotype 1 belonging to the genus Avulavirus, subfamily Paramyxovirinae, family Paramyxoviridae [9]. In Egypt, NDV has been reported since 1948 [10] then the country became endemic. Despite adopting vaccination programs that 
include both live attenuated and inactivated vaccines, the NDV continues to impact the Egyptian poultry industry $[11,12]$. The NDV outbreaks are commonly associated with the virulent NDV Genotype VII (vNDV); however, the continuous outbreaks of vNDV were also attributed to poor flock immunity and improper vaccination practices $[13,14]$.

Though over 24 commercial inactivated AI H5 vaccines are licensed for use in poultry in Egypt, the genetic mismatch with poor reactivity of these vaccines to the currently circulating viruses has led to the failure of the HPAI vaccination strategy among poultry in Egypt $[3,15]$. The spread and co-circulation of different HPAI-H5N1, HPAI-H5N8, and vNDV viruses further complicated the epidemiological situation and control strategies in Egypt with increased economic losses in poultry production. Hence, combined vaccines with matching strains were suggested to facilitate the vaccination programs and minimize the economic losses.

In this study, a trivalent HPAI-H5N1 and NDVinactivated oil-emulsion vaccine was developed, and its efficacy was evaluated in specific pathogen-free (SPF) broiler chickens against challenge with different clades HPAI-H5N1, HPAI-H5N8 clade 2.3.4.4b, and vNDV virus.

\section{Materials and Methods}

\section{Ethical approval}

Experimental procedures were reviewed and approved by the Animal Care and Use Committee (\#171101E001) of the Middle East for Veterinary Vaccines (ME VAC) Company, Egypt.

\section{Viruses}

The vaccine viruses used in this study include the reassortant AI-H5N1 viruses, rgA/Chicken/Egypt/ ME1010/2016 (H5N1) "clade 2.2.1.1" (Genbank accession No. MH558951) and rgA/Chicken/Egypt/ RG-173CAL/2017 "clade 2.2.1.2" (Genbank accession No. MG192005). Both viruses were developed using reverse genetics system [16] at the Reference Laboratory for Veterinary Quality Control on Poultry Production (RLQP), Animal Health Research Institute, Dokki, Giza, Egypt. Avirulent LaSota-like NDV strain, CK/Egypt/11478AF/2011 (Genbank accession No. MH559344) that was previously isolated and characterized was included in the vaccine [12].

Challenge viruses were selected to represent the different circulating HPAI-H5 virus clades in Egypt, including clade 2.2.1 (A/duck/EG/ M2583D/2010, Genbank accession No. CY099580), clade 2.2.1.1 (A/chicken/EG/1063/2010, Genbank accession No. KR732550), clade 2.2.1.2 (A/chicken/ EG/1575S/2015, EPI ISL 174424), and clade 2.3.4.4b (A/common-coot/EG/CA285/2016/H5N8, EPI ISL 239802). These viruses were designated HPĀI H5-2.2.1, HPAI H5-2.2.1.1, HPAI H5-2.2.1.2, and HPAI H5N8-2.3.4.4b, respectively. The vNDV challenge virus NDV/CK/Egypt/567F/2012 (Genbank accession No. JX647839) belongs to genotype VIId currently circulating in Egypt. All viruses were propagated and titrated in 10-day-old SPF eggs.

Both vaccine and challenge HPAI H5 subtype viruses were subjected to phylogenetic and sequence analyses. Phylogenetic relationships were determined with the MEGA version 6 program using the ClustalW alignment algorithm through a bootstrap of 1000 trials [17]. Nucleotide and amino acid sequence analyses were conducted using Geneious ${ }^{\circledR}$ 7.1.3 (Biomatters Ltd., New Zealand).

\section{Vaccine formulation and testing}

The vaccine seed viruses were propagated through inoculation of SPF embryonated chicken eggs through allantoic sac route inoculation. Inoculated eggs were incubated at $37^{\circ} \mathrm{C}$ for $72 \mathrm{~h}$. Harvested allantoic fluids were clarified with a low-speed centrifuger at $2000 \mathrm{rpm}$ for $10 \mathrm{~min}$ at $4^{\circ} \mathrm{C}$. The viruses were titrated in 10-day SPF embryonated chicken eggs, and then, hemagglutination (HA) titers and the egg infective dose $50\left(\right.$ EID $\left._{50}\right)$ were calculated $[18,19]$. The viruses were inactivated using $0.2 \%$ formalin (Sigma-Aldrich, Inc., Germany) and the inactivation was verified by passaging the inactivated antigens into 10-day-old SPF embryonated chicken eggs for three successive passages. The aqueous phase of the vaccine was formulated to contain doses of $10^{8}$ $\mathrm{EID}_{50} /$ dose from each virus strain and then mixed with Montanide ISA 70 VG adjuvant (SEPPIC ${ }^{\circledR}$ SA, France) at room temperature with a ratio of $70 / 30$ adjuvant/antigen $(\mathrm{v} / \mathrm{v})$. Vaccine physicochemical criteria, safety, and sterility were evaluated according to the SEPPIC Montanide ISA 70 VG technical manual and the OIE standards [19].

\section{Chicken experiments}

In all experiments, White Leghorn SPF chickens kept in biosafety level III chicken isolators were used.

\section{Birds immunization and challenge}

A total of 165, two-week-old SPF chickens were divided into 11 groups (15 birds each) and placed in biosafety level-III chicken isolators. SPF chickens in Groups 1-5 received $0.5 \mathrm{ml} /$ bird of the trivalent vaccine subcutaneously. Groups 6-10 served as challenge controls for HPAI H5-2.2.1, HPAI H5-2.2.1.1, HPAI H5-2.2.1.2, HPAI H5N8-2.3.4.4b, and vNDV viruses, respectively. The last group was inoculated with phosphate buffered saline (PBS) as a negative unvaccinated control (Table-1).

Hemagglutination inhibition (HI) antibody titers were monitored weekly by HI test. Sera of the vaccinated SPF chickens were tested using a clade 2.2.1.2 HPAI-H5N1 antigen (A/duck/EG/M2583D/2010) and a clade 2.3.4.4b HPAI-H5N8 antigen (A/common coot/EG/CA285/2016/H5N8) according to the OIE manual [19]. Virus challenge was conducted 4 weeks post-vaccination (PV) intranasally using $10^{6} \mathrm{EID}_{50} / 0.1 \mathrm{ml}$ of the AI-H5 and vNDV challenge viruses separately. The chosen challenge dose was 
Table-1: Experimental grouping and challenge viruses.

\begin{tabular}{lll}
\hline Groups & Challenge virus & Parameters \\
\hline Vaccinated $(0.5 \mathrm{ml}$ of trivalent H5ND & HPAI H5-2.2.1 (A/DU/EG/M2583D/10-H5N1) & Weekly monitoring of antibody \\
vaccine S/C) & HPAI H5-2.2.1.1 (A/CK/EG/1063/10-H5N1) & titers \\
& HPAI H5-2.2.1.2(A/CK/EG/1575S/15-H5N1) & Clinical signs \\
& HPAI H5N8-2.3.4.4b (A/common coot/EG/ & Mortality \\
& CA285/16-H5N8) & Virus shedding titers at 3, 6, and \\
& VNDV Genotype VII NDV/CK/EG/567F/12 & 10 dpc \\
Non-vaccinated & HPAI H5-2.2.1 & \\
& HPAI H5-2.2.1.1 & \\
& HPAI H5-2.2.1.2 & \\
& HPAI H5N8-2.3.4.4b & \\
& VNDV Genotype VII & \\
& PBS negative control & \\
\hline
\end{tabular}

*HPAI=Highly pathogenic avian influenza, EG=Egypt, CK=Chicken, DU=Duck, S/C=Subcutaneous, vNDV=Virulent Newcastle disease virus, dpc: Days post-challenge, PBS=Phosphate buffered saline

based on the standard dose being used in Egypt to evaluate all HPAI-H5 and NDV vaccines submitted to the Central Laboratory for Evaluation of Veterinary Biologics, Egypt. Challenged chickens were observed daily for 10 days post-challenge (dpc) for virus shedding and the presence of clinical signs, morbidity, and mortality (Table-1).

\section{Challenge virus shedding detection}

Tracheal swabs were collected from all challenged birds in $1 \mathrm{ml}$ of sterile PBS at 3, 6, and $10 \mathrm{dpc}$ to monitor virus shedding titers. Swab samples were vortexed and centrifuged at $2000 \mathrm{rpm}$ for $10 \mathrm{~min}$ at $4^{\circ} \mathrm{C}$. Supernatants were used for virus titration in 10-day-old SPF embryonated chicken eggs, and $\mathrm{EID}_{50} / \mathrm{ml}$ was calculated [18].

The cloacal samples were collected, but due to the multiple challenges and large data, we presented the data of tracheal swabs only, especially we did not find significant differences in both types of samples.

\section{Statistical analysis}

Differences in the virus shedding titers at $3 \mathrm{dpc}$ among different groups were calculated using one-way ANOVA with Tukey's post-test was performed using GraphPad Prism version 5.00 (GraphPad Software, San Diego, California, USA).

\section{Results}

Genetic analysis of the vaccine and challenge viruses Phylogenetic analysis of the HA gene of HPAI $\mathrm{H} 5 \mathrm{~N} 1$ and HPAI H5N8 viruses included in the current study revealed the clustering of the Egyptian H5N1 viruses into three distinct clades $(2.2 .1,2.2 .1 .1$, and 2.2.1.2) and the separate clustering of HPAI H5N8 into clade 2.3.4.4. Selected challenge viruses were confirmed to represent the currently circulating HPAI H5 subtype AI viruses (Figure-1). Nucleotide and amino acid sequence analyses of the vaccine seed strains and HPAI H5N8-2.3.4.4b revealed 88.7-88.8\% and 89.8$91.4 \%$ identities, respectively. Compared to HPAI $\mathrm{H} 5 \mathrm{~N} 8-2.3 .4 .4 \mathrm{~b}$, the $\mathrm{A} / \mathrm{CK} / \mathrm{EG} / \mathrm{ME} 1010 / 16$ and $\mathrm{A} / \mathrm{CK} /$ EG/RG-173CAL/17 vaccine viruses shared 10 amino acids at the studied antigenic sites and showed 16 and 18 amino acid differences, respectively (Table-2).

\section{Humoral immune response in vaccinated chickens}

Vaccinated SPF chickens elicited detectable $\mathrm{HI}$ antibody titers for HPAI-H5N1 and vNDV by 2 weeks PV using HPAI-H5N1 and NDV antigens ( $\log 26.0 \pm 1.1$ and $6.6 \pm 0.9$, respectively). The HI antibody titers using the heterologous HPAI-H5N82.3.4.4b were observed 3 weeks PV in 7 out of 15 birds, but all were seropositive 4 weeks PV (titers of $5.0 \pm 1.0 \log 2$, Table-3).

\section{Protective vaccine efficacy against different chal- lenge viruses}

\section{Clinical protection}

The negative control group did not show any clinical signs during the experiment. The HPAI-H5 challenge control birds demonstrated the typical clinical signs and post-mortem lesions by 2 dpc including edema and cyanosis of the comb and wattles and hemorrhage on shanks. Mortality reached $100 \%$ by 3 dpc. Typical vNDV clinical signs, including severe respiratory manifestations and mortalities, observed at $3 \mathrm{dpc}$ with $100 \%$ mortalities by $5 \mathrm{dpc}$. In vaccinated groups, the protection levels were $100 \%$ against HPAI H5-2.2.1.1, HPAI H5-2.2.1.2, and vNDV challenge viruses (Figure-2b, c, and e); whereas, protection levels against HPAI H5-2.2.1 and HPAI H5N8-2.3.4.4b challenge were $93.3 \%$ (Figure-2a and d). Notably, deaths in HPAI H5N8-2.3.4.4b control challenge group were observed as early as $2 \mathrm{dpc}$, and all chickens died by 3 dpc (Table-4).

\section{Challenge virus shedding}

In all vaccinated groups, the reduction of virus shedding titers was significant at $3 \mathrm{dpc}\left(\geq 3.5 \log _{10}\right.$ $\left.\mathrm{EID}_{50} / \mathrm{ml}, \mathrm{p} \leq 0.05\right)$ with a very low number of shedding birds compared to the corresponding HPAI H5 clades challenge control groups. Although $33 \%$ of chickens challenged with HPAI H5-2.2.1 shed the virus with titers of $2.1 \pm 0.6 \log _{10} \mathrm{EID}_{50} / \mathrm{ml}$ at $3 \mathrm{dpc}$, this percentage was reduced by $6 \mathrm{dpc}$ to $7.1 \%$ (1 out of 14 birds). Similarly, $20 \%$ of vaccinated chickens challenged with HPAI H5N8-2.3.4.4b shed the virus at $3 \mathrm{dpc}$, then the percentage decreased to $6.7 \%(1$ out of 15 birds) by $6 \mathrm{dpc}\left(1.7 \log _{10} \mathrm{EID}_{50} / \mathrm{ml}\right)$. The 


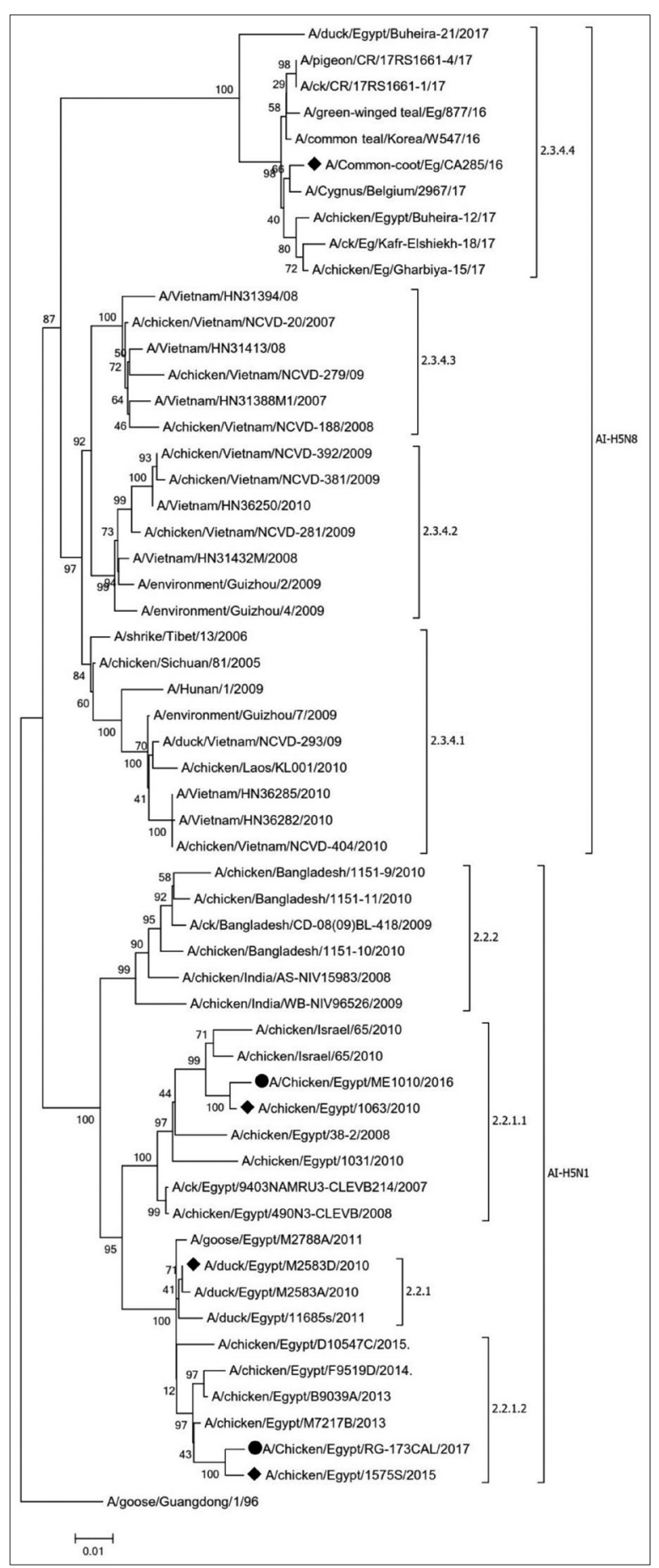

Figure-1: Phylogenetic analyses of hemagglutinin gene sequences of highly pathogenic avian influenza (HPAI) H5N1 vaccine strains (black dots) and HPAI H5N1 and H5N8 challenge strains (black rectangles) compared to the different strains from GenBank using neighbor-joining method with bootstrap values for $n=1000$ replicates.

other two vaccinated groups challenged with HPAI H5-2.2.1.1 and 2.2.1.2 viruses showed no virus shedding by $6 \mathrm{dpc}$. Similarly, the vNDV challenge group exhibited significantly reduced virus shedding titers that further diminished by 6 dpc (Table-4).

\section{Discussion}

Inadequate biosecurity and relying on vaccination as the only control strategy for the HPAI-H5N1 virus in Egypt led to frequent mutations of the virus and evolution of different subclades, especially with the use of mismatch vaccine strains $[3,20]$. In late 2016, the epidemiology of AI in Egypt exhibited a substantial change due to the emergence of HP H5N8 in wild birds [4] followed by widespread of the virus in commercial poultry [21,22]. Moreover, other poultry pathogens including vNDV and infectious bronchitis virus became more frequently diagnosed in poultry in Egypt [23].

An immunization strategy depending on using bivalent and multivalent vaccines containing whole inactivated viruses has been advocated before to control several avian pathogens [24]. The objective of the current study was to evaluate the immunogenicity and protective efficacy of a trivalent-inactivated oil-emulsion H5ND vaccine against different clades HPAI subtype $\mathrm{H} 5$ and vNDV viruses following a single-dose vaccination regimen. The vaccine contained two reassortant $\mathrm{H} 5 \mathrm{~N} 1$ viruses representing both 2.2.1.1 and 2.2.1.2 clades registered in Egypt and a LaSota-like NDV strain.

In the vaccination challenge experiments, the vaccine-induced $\mathrm{HI}$ antibody titers by 2 weeks post-vaccination against both HPAI-H5N1 and NDV antigens. However, the $\mathrm{HI}$ antibody titers against HPAI H5N8 heterologous antigens were only detectable at very low titers 3 weeks PV. By 4 weeks PV, the anti-HPAI H5N8 antibody titers were $\geq 5.0 \log 2$. These relatively low antibody titers were rather expected due to the genetic and antigenic differences in the HA between HPAI H5N1 and H5N8 viruses isolated in Egypt $[25,26]$.

The protective efficacy of the developed H5ND vaccine was evaluated by challenge of vaccinated birds with $10^{6} \mathrm{EID}_{50} / 100 \mu \mathrm{l}$ of the different clades HPAI AI viruses or vNDV at 4 weeks post-vaccination (PV). All non-vaccinated chickens showed severe clinical signs and $100 \%$ mortality by 3 and $4 \mathrm{dpc}$ in all HPAI and vNDV virus challenge groups, respectively. Although few reports indicated that HPAI H5N8 viruses produce asymptomatic disease in geese and ducks with prolonged virus shedding [27], increased virus adaptation to chickens was observed within the HPAI of 2.3.4.4 clade viruses [28,29]. This was supported by the finding that members of the HPAI H5N8 challenge group showed typical AI signs and 100\% mortality rate.

In terms of clinical protection, $100 \%$ of the vaccinated chicken groups survived challenge with HPAI H5-2.2.1.1, HPAI H5-2.2.1.2, and vNDV. Protection against HPAI H5-2.2.1 was 93.3\% accompanied by reduced shedding titers after challenge. Previous reports of an antigenic distinction between subclades 2.2.1 and 2.2.1.1 associated with substantial antigenic drifts [30,31] may explain the $6.7 \%$ mortality observed.

There was a significant $(\mathrm{p}<0.01)$ reduction in both virus shedding titers and the number of active 
Table-2: Comparison of the amino acid residues at previously reported antigenic sites in the vaccine and challenge strains.

\begin{tabular}{|c|c|c|c|c|c|c|c|}
\hline \multirow{2}{*}{ Item } & & \multicolumn{2}{|c|}{ Vaccine viruses } & \multicolumn{4}{|c|}{ Challenge viruses } \\
\hline & & $\begin{array}{c}\text { A/CK/EG/ } \\
\text { ME1010/16 } \\
2.2 .1 .1\end{array}$ & $\begin{array}{c}\text { A/CK/EG/ } \\
173 C A L / 17 \\
2.2 .1 .2\end{array}$ & $\begin{array}{c}\text { A/DU/EG/ } \\
\text { M2583D/10 } \\
2.2 .1\end{array}$ & $\begin{array}{c}\text { A/CK/EG/ } \\
1063 / 10 \\
2.2 .1 .1\end{array}$ & $\begin{array}{c}\text { A/CK/EG/ } \\
1575 S / 15 \\
2.2 .1 .2\end{array}$ & $\begin{array}{c}\text { A/common } \\
\text { coot/EG/ } \\
\text { CA285/16 } \\
2.3 .4 .4 b\end{array}$ \\
\hline \multicolumn{2}{|c|}{$\begin{array}{l}\text { Amino acid identity } \% \text { to } \\
2.3 .4 .4 \text { b H5N8 }\end{array}$} & 89.8 & 91.4 & 91.7 & 90.2 & 91.2 & - \\
\hline \multirow{33}{*}{ Antigenic sites* } & 43 & D & $\mathrm{N}$ & $\mathrm{N}$ & D & $\mathrm{N}$ & $\mathrm{D}$ \\
\hline & 71 & $\mathrm{P}$ & $\mathrm{L}$ & $\mathrm{L}$ & $P$ & L & $\mathrm{I}$ \\
\hline & 115 & $\mathrm{~K}$ & $\mathrm{Q}$ & $\mathrm{Q}$ & $\mathrm{K}$ & $\mathrm{Q}$ & $\mathrm{L}$ \\
\hline & 117 & I & I & $\mathrm{I}$ & I & I & I \\
\hline & 119 & $\mathrm{~K}$ & $\mathrm{~K}$ & $\mathrm{~K}$ & $\mathrm{~K}$ & $\mathrm{~K}$ & $\mathrm{~K}$ \\
\hline & 120 & $\mathrm{~S}$ & $\mathrm{D}$ & $\mathrm{D}$ & $\mathrm{S}$ & $\mathrm{D}$ & $\mathrm{S}$ \\
\hline & 123 & $\mathrm{P}$ & $\mathrm{S}$ & $\mathrm{S}$ & $\mathrm{P}$ & $\mathrm{S}$ & $\mathrm{P}$ \\
\hline & 124 & $\mathrm{D}$ & D & $\mathrm{D}$ & $\mathrm{D}$ & $\mathrm{D}$ & $\mathrm{N}$ \\
\hline & 126 & $E$ & $\mathrm{E}$ & $E$ & $E$ & $E$ & $E$ \\
\hline & 127 & $A$ & A & $A$ & $A$ & $A$ & $\mathrm{~T}$ \\
\hline & 129 & $\mathrm{~L}$ & - & - & $\mathrm{L}$ & - & $\mathrm{L}$ \\
\hline & 138 & $\mathrm{Q}$ & Q & $\mathrm{Q}$ & $\mathrm{Q}$ & $\mathrm{Q}$ & $\mathrm{Q}$ \\
\hline & 140 & $\mathrm{G}$ & $R$ & $\mathrm{R}$ & $\mathrm{G}$ & $\mathrm{R}$ & $T$ \\
\hline & 141 & $P$ & S & $\mathrm{S}$ & $\mathrm{S}$ & S & $P$ \\
\hline & 144 & $Y$ & $\mathrm{~F}$ & $\mathrm{~F}$ & $Y$ & $\mathrm{~F}$ & $\mathrm{~F}$ \\
\hline & 151 & I & $\mathrm{T}$ & $\mathrm{T}$ & I & T & I \\
\hline & 154 & $\mathrm{~N}$ & $\mathrm{~N}$ & $\mathrm{~N}$ & $\mathrm{~N}$ & $\mathrm{~N}$ & $\mathrm{~N}$ \\
\hline & 155 & $\mathrm{~N}$ & $\mathrm{G}$ & $D$ & $\mathrm{~N}$ & D & D \\
\hline & 156 & $\mathrm{~T}$ & A & A & $\mathrm{T}$ & A & A \\
\hline & 158 & $P$ & $P$ & $P$ & $P$ & $P$ & $P$ \\
\hline & 159 & $\mathrm{~T}$ & $T$ & $\mathrm{~T}$ & $\mathrm{~T}$ & $\mathrm{~T}$ & $\mathrm{~T}$ \\
\hline & 162 & $E$ & K & $\mathrm{K}$ & $E$ & $\mathrm{~K}$ & I \\
\hline & 163 & $\mathrm{~S}$ & $\mathrm{~S}$ & $\mathrm{~S}$ & $\mathrm{~S}$ & $\mathrm{~S}$ & $\mathrm{~S}$ \\
\hline & 165 & $\mathrm{H}$ & $\mathrm{N}$ & $\mathrm{N}$ & $\mathrm{H}$ & $\mathrm{N}$ & $\mathrm{N}$ \\
\hline & 174 & V & V & V & V & V & $\mathrm{I}$ \\
\hline & 181 & $P$ & $P$ & $P$ & $P$ & $P$ & $\mathrm{~S}$ \\
\hline & 189 & $\mathrm{R}$ & $\mathrm{R}$ & $\mathrm{R}$ & $\mathrm{R}$ & $\mathrm{R}$ & $\mathrm{N}$ \\
\hline & 190 & $\mathrm{I}$ & $\mathrm{L}$ & $\mathrm{L}$ & I & $\mathrm{L}$ & $\mathrm{L}$ \\
\hline & 192 & $\mathrm{~K}$ & $\mathrm{Q}$ & $\mathrm{Q}$ & $\mathrm{K}$ & $\mathrm{Q}$ & $\mathrm{K}$ \\
\hline & 195 & $\mathrm{~T}$ & $T$ & $\mathrm{~T}$ & $\mathrm{~T}$ & $T$ & $T$ \\
\hline & 198 & I & I & $\mathrm{I}$ & I & I & I \\
\hline & 223 & $\mathrm{~S}$ & $\mathrm{~S}$ & $\mathrm{~S}$ & $\mathrm{~S}$ & $\mathrm{~S}$ & $\mathrm{R}$ \\
\hline & 226 & V & $M$ & $M$ & V & $M$ & $M$ \\
\hline
\end{tabular}

*Residues in the vaccine strains that are identical to HPAI H5N8-2.3.4.4b (A/common coot/EG/CA285/2016) are gray shaded, the studied antigenic sites are previously reported by Duvvuri et al., Kaverin et al., Kaverin et al., Khurana et al. and Sun et al. [33-37]. HPAI=Highly pathogenic avian influenza, EG=Egypt, CK=Chicken, DU=Duck, PBS=Phosphate buffered saline

Table-3: Mean HI antibody titers and seropositivity percentages in vaccinated birds.

\begin{tabular}{|c|c|c|c|c|c|c|}
\hline \multirow[t]{3}{*}{ Weeks PV } & \multicolumn{6}{|c|}{ Type of Antigen used for HI test ${ }^{1}$} \\
\hline & \multicolumn{2}{|c|}{ HPAI H5N1-2.2.1 } & \multicolumn{2}{|c|}{ HPAI H5N8-2.3.4.4b } & \multicolumn{2}{|c|}{ NDV-Ag } \\
\hline & Mean $\pm S^{2} D^{2}$ & Positivity ${ }^{30}$ & Mean \pm SD & Positivity \% & Mean \pm SD & Positivity \% \\
\hline 1 & $0.0 \pm 0.0$ & 0 & $0.0 \pm 0.0$ & 0 & $0.0 \pm 0.0$ & 0 \\
\hline 2 & $6.0 \pm 1.1$ & 100 & $0.0 \pm 0.0$ & 0 & $6.6 \pm 0.9$ & 100 \\
\hline 3 & $9.2 \pm 0.8$ & 100 & $2.6 \pm 0.8$ & 46.7 & $8.4 \pm 0.6$ & 100 \\
\hline 4 & $9.8 \pm 0.5$ & 100 & $5.0 \pm 1.0$ & 100 & $8.9 \pm 0.6$ & 100 \\
\hline
\end{tabular}

${ }^{1} \mathrm{HI}=$ Hemagglutination inhibition test, HPAI H5-2.2.1 AI-H5N1 antigen=A/duck/EG/M2583D/2010, HPAI H5N8-2.3.4.4b antigen (A/common coot/EG/CA285/2016/H5N8). HPAI=Highly pathogenic avian influenza, ${ }^{2} \mathrm{SD}=$ Standard deviation, ${ }^{3}$ Positivity $\%=$ Number of seropositive birds/total tested $\times 100$. PV=Post-vaccination, $\mathrm{HI}=$ Hemagglutination inhibition

virus shedders in all challenged groups, including those receiving HPAI H5-2.3.4.4b, despite the low $\mathrm{HI}$ antibody titers against HPAI-H5N8-2.3.4.4 clade virus. In contrast, Yuk et al. [32] showed that while commercial clade 2.3.2 H5 vaccines protected chickens against HPAI-H5N8 virus challenge, they failed to prevent virus shedding. It is worthwhile to note that the seed virus of clade 2.3.2 viruses showed $84.6-87.7 \%$ amino acid identities with the HPAI H5N8 challenge virus, compared to $89.8-91.4 \%$ in the current study.

In another study, the efficacy of commercial vaccines available in Egypt was studied. Most of the 


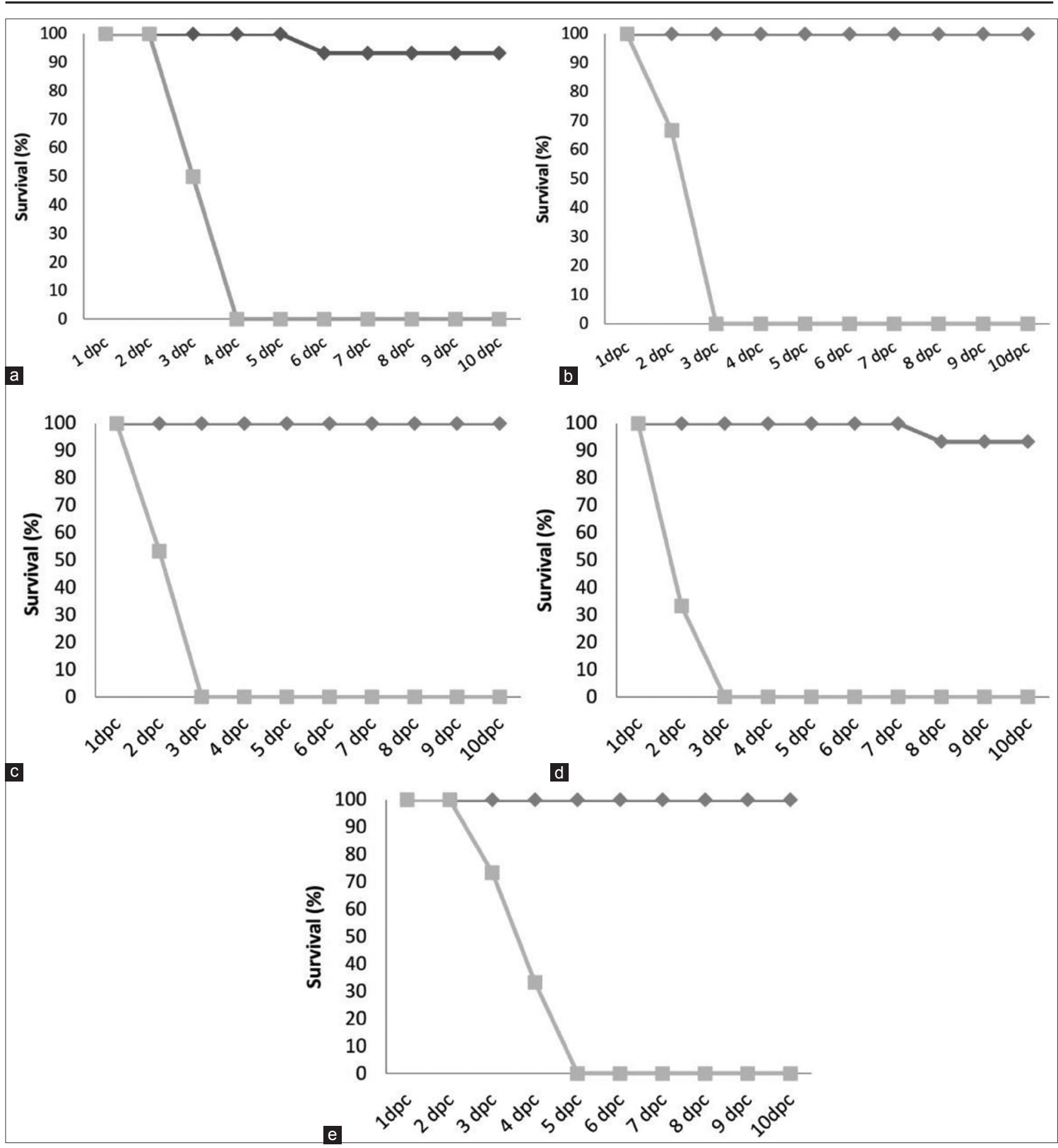

Figure-2: (a-e) Survival rates in the H5ND-vaccinated birds post-challenge with different clades highly pathogenic avian influenza H5N1, H5N8, and virulent Newcastle disease viruses.

vaccines did not exceed $80 \%$ of protection and did not prevent virus shedding with the exception of a commercial vaccine based on a clade 2.3.4 $\mathrm{H} 5 \mathrm{~N} 1$ virus that reduced virus shedding [25]. In this study, we used two HPAI-H5N1 viruses belonging to two different clades that are $89.8-91.4 \%$ identical to the HPAI H5N8-2.3.4.4 on the amino acid level. In addition, both viruses share several amino acids that are distributed at the previously reported antigenic sites [33-37]. The aforementioned factors may explain the observed protection, relatively better $\mathrm{HI}$ antibody titers, and reduced virus shedding titers, compared to previous studies $[25,38,39]$. Moreover, previous reports indicated that changes in HA amino acids may not correspond to both clade and subclade grouping and the protective efficacy of vaccine preparations [35].

Although the protection rate $(\geq 90 \%)$ against HPAI-H5N8-2.3.4.4b is acceptable for a combined vaccine and the vaccine could be regarded as effective, this finding cannot be extrapolated to the field conditions considering the first 3 weeks gap observed until a relatively high cross antibody titers are detected. The complicated poultry field situation and inadequate biosecurity measures may reduce the efficacy 
Table-4: Challenge virus shedding titers in vaccinated and non-vaccinated challenged control groups.

\begin{tabular}{|c|c|c|c|c|c|c|}
\hline \multirow[t]{2}{*}{ Group } & \multirow[t]{2}{*}{ dpc $^{1}$} & \multicolumn{5}{|c|}{ Challenge virus shedding titers $\operatorname{EID}_{50} / \mathrm{ml}$ (number of positives/total tested) ${ }^{2}$} \\
\hline & & HPAI H5-2.2.1 & HPAI H5-2.2.1.1 & HPAI H5-2.2.1.2 & HPAI H5N8-2.3.4.4b & vNDV \\
\hline H5ND- & 3 & $2.1 \pm 0.66^{\mathrm{a}}(5 / 15)$ & $2.2 \pm 0.76^{\mathrm{a}}(3 / 15)$ & $1.8 \pm 0.81^{\mathrm{a}}(4 / 15)$ & $1.3 \pm 0.01^{\mathrm{a}}(3 / 15)$ & $2.1 \pm 0.3^{\mathrm{a}}(6 / 15)$ \\
\hline vaccinated & 6 & $2.8 \pm 0.0(1 / 14)$ & $0(0 / 15)$ & $0(0 / 15)$ & $1.7 \pm 0.0(1 / 15)$ & $1.9 \pm 0.5(2 / 15)$ \\
\hline groups & 10 & $0(0 / 14)$ & $0(0 / 15)$ & $0(0 / 15)$ & $0(0 / 14)$ & $0(0 / 15)$ \\
\hline Challenge & 2 & $\mathrm{NT}^{3}$ & NT & NT & $4.5 \pm 0.6$ & NT \\
\hline \multirow[t]{5}{*}{ control $^{4}$} & 3 & $5.8 \pm 0.47^{b}(15 / 15)$ & $5.7 \pm 0.72^{\mathrm{b}}(15 / 15)$ & $5.9 \pm 0.54^{b}(15 / 15)$ & $3.9 \pm 0.4^{b}(5 / 5)$ & $4.8 \pm 0.7^{b}(15 / 15)$ \\
\hline & 4 & $5.7 \pm 0.46(4 / 4)$ & -- & $6.4 \pm 0.31(5 / 5)$ & -- & $4.3 \pm 0.6$ \\
\hline & 5 & -- & -- & -- & -- & $5.1 \pm 0.7$ \\
\hline & 6 & -- & -- & -- & -- & -- \\
\hline & 10 & -- & -- & -- & -- & -- \\
\hline $\begin{array}{l}\text { PBS negative } \\
\text { control }\end{array}$ & All & & & Not detected & & \\
\hline
\end{tabular}

${ }^{1} \mathrm{dpc}=$ Days post-challenge-additional days in challenge control groups are the days at which deaths of infected birds occur; ${ }^{2}$ Virus shedding titers at the same column at ${ }^{3} \mathrm{dpc}$ and followed by different superscript small letters indicate significant differences $(p \leq 0.05) ;{ }^{3} \mathrm{NT}=$ Not tested, ${ }^{4} \mathrm{All}$ birds died by $3-4 \mathrm{dpc}$, HPAI=Highly pathogenic avian influenza, PBS $=$ Phosphate buffered saline

of the HPAI H5N1 vaccines against HPAI-H5N82.3.4.4b compared to experimental studies. Therefore, studies of different vaccination strategies (e.g., double dose regimen) and/or vaccine development for better control of clade 2.3.4.4b HPAI H5N8 in Egypt may be needed [25].

\section{Conclusion}

The trivalent H5ND vaccine was found to be immunogenic, and it provides protection in SPF chickens against HPAI H5 AI and virulent ND infections. The current study also demonstrates that the multivalent oil-emulsion vaccines could be a useful strategy to simplify the vaccination programs for controlling multiple poultry viruses, especially in endemic countries.

\section{Authors' Contributions}

AA, MS, WHK, AN, and AAA: Conceptualization and design of the study. AA, MS, WHK, AN, AAS, MAZ, and AMD: Conducted the experiment, analyzed, and interpreted the data. AA, WHK, and AAA: Writing and revising the manuscript. All authors: Reviewing, editing, and approved the final manuscript.

\section{Acknowledgments}

The authors would like to thank the laboratory animal teams at the ME VAC ${ }^{\circ}$ Co. and the RLQP, Animal Health Research Institute at Egypt for their technical support during experimental studies. This work was funded by Reference Laboratory for Veterinary Quality Control on Poultry Production, Animal Health Research Institute, Dokki, Giza 12618, Egypt and Middle East for Veterinary Vaccines (ME VAC) Company.

\section{Competing Interests}

The authors declare that they have no competing interests. ME VAC company had no role in the study design, data analysis and/or the decision of publication of the current study

\section{Publisher's Note}

Veterinary World remains neutral with regard to jurisdictional claims in published institutional affiliation.

\section{References}

1. Tong, S., Zhu, X., Li, Y., Shi, M., Zhang, J., Bourgeois, M., Yang, H., Chen, X., Recuenco, S., Gomez, J., Chen, L.M., Johnson, A., Tao, Y., Dreyfus, C., Yu, W., McBride, R., Carney, P.J., Gilbert, A.T., Chang, J., Guo, Z., Davis, C.T., Paulson, J.C., Stevens, J., Rupprecht, C.E., Holmes, E.C., Wilson, I.A. and Donis, R.O. (2013) New world bats harbor diverse influenza a viruses. PLoS Pathog., 9(10): e1003657.

2. El-Zoghby, E.F., Arafa, A.S., Hassan, M.K., Aly, M.M., Selim, A., Kilany, W.H., Selim, U., Nasef, S., Aggor, M.G., Abdelwhab, E.M. and Hafez, H.M. (2012) Isolation of H9N2 avian influenza virus from bobwhite quail (Colinus virginianus) in Egypt. Arch. Virol., 157(6): 1167-1172.

3. Kayali, G., Kandeil, A., El-Shesheny, R., Kayed, A.S., Maatouq, A.M., Cai, Z., McKenzie, P.P., Webby, R.J., El Refaey, S., Kandeel, A. and Ali, M.A. (2016) Avian influenza A(H5N1) virus in Egypt. Emerg.Infect. Dis., 22(3): 379-388.

4. Selim, A.A., Erfan, A.M., Hagag, N., Zanaty, A., Samir, A.H., Samy, M., Abdelhalim, A., Arafa, A.A., Soliman, M.A., Shaheen, M., Ibraheem, E.M., Mahrous, I., Hassan, M.K. and Naguib, M.M. (2017) Highly pathogenic avian influenza virus (H5N8) Clade 2.3.4.4 infection in migratory birds, Egypt. Emerg. Infect.Dis., 23(6): 1048-1051.

5. Naguib, M.M., Arafa, A.S., El-Kady, M.F., Selim, A.A., Gunalan, V., Maurer-Stroh, S., Goller, K.V., Hassan, M.K., Beer, M., Abdelwhab, E.M. and Harder, T.C. (2015) Evolutionary trajectories and diagnostic challenges of potentially zoonotic avian influenza viruses $\mathrm{H} 5 \mathrm{~N} 1$ and H9N2 co-circulating in Egypt. Infect. Genet. Evol., 34(1): 278-291.

6. Arafa, A.S., Naguib, M.M., Luttermann, C., Selim, A.A., Kilany, W.H., Hagag, N., Samy, A., Abdelhalim, A., Hassan, M.K., Abdelwhab, E.M., Makonnen, Y., Dauphin, G., Lubroth, J., Mettenleiter, T.C., Beer, M., Grund, C. and Harder, T.C. (2015) Emergence of a novel cluster of influenza $\mathrm{A}(\mathrm{H} 5 \mathrm{~N} 1)$ virus clade 2.2.1.2 with putative human health impact in Egypt, 2014/15. Euro Surveill., 20(13): 2-8.

7. Salaheldin, A.H., Veits, J., El-Hamid, H.S.A., Harder, T.C., Devrishov, D., Mettenleiter, T.C., Hafez, H.M. and Abdelwhab, E.M. (2017) Isolation and genetic 
characterization of a novel 2.2.1.2a H5N1 virus from a vaccinated meat-turkeys flock in Egypt. Virol. J., 14(1): 48.

8. Samy, A.A., El-Enbaawy, M.I., El-Sanousi, A.A., Nasef, S.A., Naguib, M.M., Abdelwhab, E.M., Hikono, H. and Saito, T. (2016) Different counteracting host immune responses to clade 2.2.1.1 and 2.2.1.2 Egyptian H5N1 highly pathogenic avian influenza viruses in naive and vaccinated chickens. Vet. Microbiol., 183: 103-109.

9. Lamb, R.A., Collins, P.L., Kolakofsky, D., Melero, J.A., Nagai, Y., Oldstone, M.B.A., Pringle, C.R. and Rima, B.K. (2005) Family Paramyxoviridae. In: Fauquet CM, editor. Virus Taxonomy: The Classification and Nomenclature of Viruses the Eighth Report of the International Committee on Taxonomy of Viruses. Elsevier Academic Press, London. p655-668.

10. Daubney, R. and Mansy, W. (1948) The occurrence of Newcastle disease in Egypt. J. Comp. Pathol. Ther., 58(3): 189-200.

11. Radwan, M.M., Darwish, S.F., El-Sabagh, I.M., El-Sanousi, A.A. and Shalaby, M.A. (2013) Isolation and molecular characterization of Newcastle disease virus genotypes II and VIId in Egypt between 2011 and 2012. Virus Genes, 47(2): 311-316.

12. Kilany, W.H., Ali, A., Bazid, A.I., Zain El-Abideen, M.A. and El Sayed, M.A. (2015) Evaluation of two inactivated Newcastle disease virus vaccines (Genotype II and VII) against challenge of Newcastle disease genotype VII infection in chicken. J. Anim. Vet. Adv., 14(7): 211-218.

13. Alexander, D.J., Manvell, R.J., Lowings, J.P., Frost, K.M., Collins, M.S., Russell, P.H. and Smith, J.E. (1997) Antigenic diversity and similarities detected in avian paramyxovirus Type 1 (Newcastle disease virus) isolates using monoclonal antibodies. Avian Pathol., 26(2): 399-418.

14. Dortmans, J.C., Peeters, B.P. and Koch, G. (2012) Newcastle disease virus outbreaks: Vaccine mismatch or inadequate application? Vet. Microbiol., 160(1-2): 17-22.

15. Bertran, K., Moresco, K. and Swayne, D.E. (2015) Impact of vaccination on infection with Vietnam H5N1 high pathogenicity avian influenza virus in hens and the eggs they lay. Vaccine, 33(11): 1324-1330.

16. Hoffmann, E., Neumann, G., Kawaoka, Y., Hobom, G. and Webster, R.G. (2000) A DNA transfection system for generation of influenza a virus from eight plasmids. Proc. Natl. Acad. Sci. U. S. Am., 97(11): 6108-6113.

17. Tamura, K., Stecher, G., Peterson, D., Filipski, A. and Kumar, S. (2013) MEGA6: Molecular evolutionary genetics analysis version 6.0. Mol. Biol. Evol., 30(12): 2725-2729.

18. Reed, L.J. and Muench, H. (1938) A simple method of estimating fifty percent endpoint. Am. J. Epidemiol., 27(3): 493-497.

19. Swayne, D. and Brown, I. (2015) Avian influenza. In: Manual of Diagnostic Tests and Vaccines for Terrestrial Animal. OIE, Paris, France.

20. Arafa, A., Suarez, D., Kholosy, S.G., Hassan, M.K., Nasef, S., Selim, A., Dauphin, G., Kim, M., Yilma, J., Swayne, D. and Aly, M.M. (2012) Evolution of highly pathogenic avian influenza H5N1 viruses in Egypt indicating progressive adaptation. Arch. Virol., 157(10): 1931-1947.

21. Salaheldin, A.H., El-Hamid, H.S., Elbestawy, A.R., Veits, J., Hafez, H.M., Mettenleiter, T.C. and Abdelwhab, E.M. (2018) Multiple introductions of influenza A(H5N8) virus into poultry, Egypt, 2017. Emerg. Infect. Dis., 24(5): 10.

22. Yehia, N., Naguib, M.M., Li, R., Hagag, N., El-Husseiny, M., Mosaad, Z., Nour, A., Rabea, N., Hasan, W.M., Hassan, M.K., Harder, T. and Arafa, A.A. (2018) Multiple introductions of reassorted highly pathogenic avian influenza viruses (H5N8) clade 2.3.4.4b causing outbreaks in wild birds and poultry in Egypt. Infect. Genet. Evol., 58: 56-65.

23. Hassan, K.E., Shany, S.A., Ali, A., Dahshan, A.H., El-Sawah, A.A. and El-Kady, M.F. (2016) Prevalence of avian respiratory viruses in broiler flocks in Egypt. Poult. Sci., 95(6): 1271-1280.
24. Lee, D.H., Park, J.K., Kwon, J.H., Yuk, S.S., ErdeneOchir, T.O., Jang, Y.H., Seong, B.L., Lee, J.B., Park, S.Y., Choi, I.S. and Song, C.S. (2013) Efficacy of single dose of a bivalent vaccine containing inactivated Newcastle disease virus and reassortant highly pathogenic avian influenza H5N1 virus against lethal HPAI and NDV infection in chickens. PLoS One, 8(3): e58186.

25. Kandeil, A., Sabir, J.S.M., Abdelaal, A., Mattar, E.H., El-Taweel, A.N., Sabir, M.J., Khalil, A.A., Webby, R., Kayali, G. and Ali, M.A. (2018) Efficacy of commercial vaccines against newly emerging avian influenza H5N8 virus in Egypt. Sci. Rep., 8(1): 9697.

26. Voronina, O.L., Ryzhova, N.N., Aksenova, E.I., Kunda, M.S., Sharapova, N.E., Fedyakina, I.T., Chvala, I.A., Borisevich, S.V., Logunov, D.Y. and Gintsburg, A.L. (2018) Genetic features of highly pathogenic avian influenza viruses $\mathrm{A}(\mathrm{H} 5 \mathrm{~N} 8)$, isolated from the European part of the Russian Federation. Infect. Genet. Evol., 63: 144-150.

27. Son, K., Kim, Y.K., Oem, J.K., Jheong, W.H., Sleeman, J.M. and Jeong, J. (2018) Experimental infection of highly pathogenic avian influenza viruses, clade 2.3.4.4 H5N6, and H5N8, in Mandarin ducks from South Korea. Transbound. Emerg. Dis., 65(3): 899-903.

28. DeJesus, E., Costa-Hurtado, M., Smith, D., Lee, D.H., Spackman, E., Kapczynski, D.R., Torchetti, M.K., Killian, M.L., Suarez, D.L., Swayne, D.E. and PantinJackwood, M.J. (2016) Changes in adaptation of H5N2 highly pathogenic avian influenza $\mathrm{H} 5$ clade 2.3 .4 .4 viruses in chickens and mallards. Virology, 499(1): 52-64.

29. Pantin-Jackwood, M.J., Costa-Hurtado, M., Bertran, K., DeJesus, E., Smith, D. and Swayne, D.E. (2017) Infectivity, transmission and pathogenicity of $\mathrm{H} 5$ highly pathogenic avian influenza clade 2.3.4.4 (H5N8 and H5N2) United States index viruses in Pekin ducks and Chinese geese. Vet. Res., 48(1): 33.

30. Watanabe, Y., Ibrahim, M.S., Ellakany, H.F., Kawashita, N., Daidoji, T., Takagi, T., Yasunaga, T., Nakaya, T. and Ikuta, K. (2012) Antigenic analysis of highly pathogenic avian influenza virus $\mathrm{H} 5 \mathrm{~N} 1$ sublineages co-circulating in Egypt. $J$. Gen. Virol., 93(Pt 10): 2215-2226.

31. Younan, M., Poh, M.K., Elassal, E., Davis, T., Rivailler, P., Balish, A.L., Simpson, N., Jones, J., Deyde, V., Loughlin, R., Perry, I., Gubareva, L., ElBadry, M.A., Truelove, S., Gaynor, A.M., Mohareb, E., Amin, M., Cornelius, C., Pimentel, G., Earhart, K., Naguib, A., Abdelghani, A.S., Refaey, S., Klimov, A.I., Donis, R.O. and Kandeel, A. (2013) Microevolution of highly pathogenic avian influenza $\mathrm{A}(\mathrm{H} 5 \mathrm{~N} 1)$ viruses isolated from humans, Egypt, 2007-2011. Emerg. Infect. Dis., 19(1): 43-50.

32. Yuk, S.S., Erdene-Ochir, T.O., Kwon, J.H., Noh, J.Y., Hong, W.T., Jeong, J.H., Jeong, S., Gwon, G.B., Shin, J.I., Sur, J.H. and Song, C.S. (2017) Efficacy of clade 2.3.2 H5 commercial vaccines in protecting chickens from clade 2.3.4.4 H5N8 highly pathogenic avian influenza infection. Vaccine, 35(9): 1316-1322.

33. Duvvuri, V.R., Duvvuri, B., Cuff, W.R., Wu, G.E. and $\mathrm{Wu}$, J. (2009) Role of positive selection pressure on the evolution of H5N1 hemagglutinin. Genomics Proteomics Bioinformatics, 7(1-2): 47-56.

34. Kaverin, N.V., Rudneva, I.A., Ilyushina, N.A., Varich, N.L., Lipatov, A.S., Smirnov, Y.A., Govorkova, E.A., Gitelman, A.K., Lvov, D.K. and Webster, R.G. (2002) Structure of antigenic sites on the haemagglutinin molecule of $\mathrm{H} 5$ avian influenza virus and phenotypic variation of escape mutants. J. Gen. Virol., 83(Pt 10): 2497-2505.

35. Kaverin, N.V., Rudneva, I.A., Govorkova, E.A., Timofeeva, T.A., Shilov, A.A., Kochergin-Nikitsky, K.S., Krylov, P.S. and Webster, R.G. (2007) Epitope mapping of the hemagglutinin molecule of a highly pathogenic H5N1 influenza virus by using monoclonal antibodies. J. Virol., 81(23): 12911-12917. 
36. Khurana, S., Suguitan, A.L Jr., Rivera, Y., Simmons, C.P., Lanzavecchia, A., Sallusto, F., Manischewitz, J., King, L.R., Subbarao, K. and Golding, H. (2009) Antigenic fingerprinting of $\mathrm{H} 5 \mathrm{~N} 1$ avian influenza using convalescent sera and monoclonal antibodies reveals potential vaccine and diagnostic targets. PLoS Med., 6(4): e1000049.

37. Sun, L., Lu, X., Li, C., Wang, M., Liu, Q., Li, Z., Hu, X., Li, J., Liu, F., Li, Q., Belser, J.A., Hancock, K., Shu, Y., Katz, J.M., Liang, M. and Li, D. (2009) Generation, characterization and epitope mapping of two neutralizing and protective human recombinant antibodies against influenza A H5N1 viruses. PLoS One, 4(5): e5476.

38. Kapczynski, D.R., Pantin-Jackwood, M.J., Spackman, E.,
Chrzastek, K., Suarez, D.L. and Swayne, D.E. (2017) Homologous and heterologous antigenic matched vaccines containing different $\mathrm{H} 5$ hemagglutinins provide variable protection of chickens from the 2014 U.S. H5N8 and H5N2 clade 2.3.4.4 highly pathogenic avian influenza viruses. Vaccine, 35(46): 6345-6353.

39. Santos, J.J.S., Obadan, A.O., Garcia, S.C., Carnaccini, S., Kapczynski, D.R., Pantin-Jackwood, M., Suarez, D.L. and Perez, D.R. (2017) Short and long-term protective efficacy against clade 2.3.4.4 H5N2 highly pathogenic avian influenza virus following prime-boost vaccination in Turkeys. Vaccine, 35(42): 5637-5643.

$* * * * * * * *$ 